\title{
Authors' reply to Colquhoun and Buchinsky
}

\author{
Jason M R Gill reader ${ }^{1}$, Carlos A Celis-Morales research associate ${ }^{1}$, Naveed Sattar professor ${ }^{1}$, Jill \\ $\mathrm{P}$ Pell professor ${ }^{2}$
}

${ }^{1}$ BHF Glasgow Cardiovascular Research Centre, Institute of Cardiovascular and Medical Sciences, University of Glasgow, G12 8TA, UK; ${ }^{2}$ Institute of Health and Wellbeing, University of Glasgow, Glasgow, UK

Colquhoun makes an important comment about reverse causality in our study of active commuting. ${ }^{12}$ We excluded people with reported prevalent disease at baseline but cannot exclude the possibility that including those with subclinical or undiagnosed disease at baseline could have influenced the findings. In the manuscript we originally submitted we simply considered two groups of commuters-active and non-active. We tried to minimise the potential contribution of reverse causality by undertaking a sensitivity landmark analysis, which excluded all events occurring in the first year of follow-up. This did not alter the main findings.

In the review process we were asked to consider commuting by cycle and by foot separately and to consider mixed mode commuting. This additional analysis strengthened the paper, but having more groups reduced the number of events in each group, leaving insufficient power to perform the landmark analysis we undertook in the original version. This analysis will be possible in future when more events have accrued. We thought that we had mentioned reverse causality as a limitation in the discussion, but on re-reading realised that we had not. We should have done, and we thank Colquhoun for his valid point.

We adjusted for a comprehensive range of potential confounders in our analyses, but residual confounding is always a possibility in observational studies, which we acknowledge in the paper. Observational data cannot show causality; randomised controlled trials (RCTs) are the gold standard for establishing causality. But RCTs are not always feasible for answering research questions of this nature, owing to the relatively low event rate in the general population. For example, it took 23 years of follow-up in the Da Qing RCT to show that lifestyle intervention reduced risk of mortality from cardiovascular disease and all causes. ${ }^{3}$ Shorter term RCTs, however, show clear evidence of improvements in health biomarkers in those randomised to active commuting. ${ }^{45}$

Buchinsky and others asked about the thresholds used to divide walking and cycling commuters into long and short duration. ${ }^{6}$ This was based on the median weekly commuting distance for each group, which was six miles a week for walkers and 30 miles a week for cyclists.

\section{Competing interests: We are the authors of this paper.}

Full response at: http://www.bmj.com/content/357/bmj.j1456/rr-3.

1 Colquhoun D. Benefits of active commuting - causality matters. BMJ 2017:357:j2425.

2 Celis-Morales CA, Lyall DM, Welsh P, et al. Association between active commuting and incident cardiovascular disease, cancer, and mortality: prospective cohort study. BMJ 2017;357:j1456. doi:10.1136/bmj.j1456 pmid:28424154.

3 Li G, Zhang P, Wang J, et al. Cardiovascular mortality, all-cause mortality, and diabetes incidence after lifestyle intervention for people with impaired glucose tolerance in the Da Qing Diabetes Prevention Study: a 23-year follow-up study. Lancet Diabetes Endocrinol 2014:357:474-80. doi:10.1016/S2213-8587(14)70057-9 pmid:24731674.

4 Østergaard L, Børrestad LA, Tarp J, Andersen LB. Bicycling to school improves the cardiometabolic risk factor profile: a randomised controlled trial. BMJ Open 2012;357:e001307. doi:10.1136/bmjopen-2012-001307 pmid:23117560.

5 Møller NC, Østergaard L, Gade JR, Nielsen JL, Andersen LB. The effect on cardiorespiratory fitness after an 8-week period of commuter cycling - a randomized controlled study in adults. Prev Med 2011;357:172-7. doi:10.1016/.ypmed.2011.06. 007 pmid:21708185.

6 Buchinsky F. How were long and short commuting distances defined?BMJ 2017;357:j2442. Published by the BMJ Publishing Group Limited. For permission to use (where not already granted under a licence) please go to http://group.bmj.com/group/rights-licensing/ permissions 